\title{
Art and astronomy: my personal experience
}

\author{
Guellen \\ 17, Rue de Pen Carn \\ 29500 Ergué-Gabéric, France \\ email: guellen@voila.fr
}

\begin{abstract}
Astronomy and Art, two worlds seemingly opposite. One scientific and rigorous, the other perceived as light and whimsical. But if these two worlds were united? If art gave itself to the service of science? If fantasy became a playful pretext to transmit knowledge to young children? I recount here my experience, that of a meeting, and of an adventure. How and why an astronomy book for the very young emerged from the collaboration between a painter and an astronomer of the Observatory of Paris.
\end{abstract}

Keywords. art, paintings

\section{Introduction}

I have been asked to contribute to this symposium for a number of reasons. First, because I am a painter. My name, as an artist, is Guellen and I created the image that illustrates the poster of the symposium. The second reason for my presence here is that, in collaboration with an astronomer from the Observatoire de Paris, I am producing a series of books on astronomy for children. Third, I find it interesting to speak about my vision of the two universes of science and art which so rarely have the opportunity to come together. And, fourth, to touch on the rôle that art can play, at the service of science, through the use of books for young children.

\section{My work}

So, I am a painter. I use an unusual and complex technique. A style which is playful and attracts the interest of children as well as adults. It needs a little explaining, which I will do under three headings: texture, colours and the subject matter.

Texture is above all the search for materials and the interplay of different thicknesses, developed over the years as a result of numerous experiments. Collages play an essential rôle. The structure is made up of crumpled paper, torn material, pieces from jig-saw puzzles and, also, pieces of lace or corrugated cardboard. All this creates an intriguing texture and the marriage of different materials is an invitation to touch the painting with the tips of the fingers.

The colours are warm. People have often compared my paintings to church windows because the colours are so luminous. They incorporate a palette of brilliant and contrasting hues which form a whirlwind of light and energy.

My inspiration comes from my celtic origins. I was born, and live in Brittany, a little corner of France lying between the Land and the Sea. A region which has kept its roots and has preserved its culture, including the mysterious legends which accompanied my childhood. 


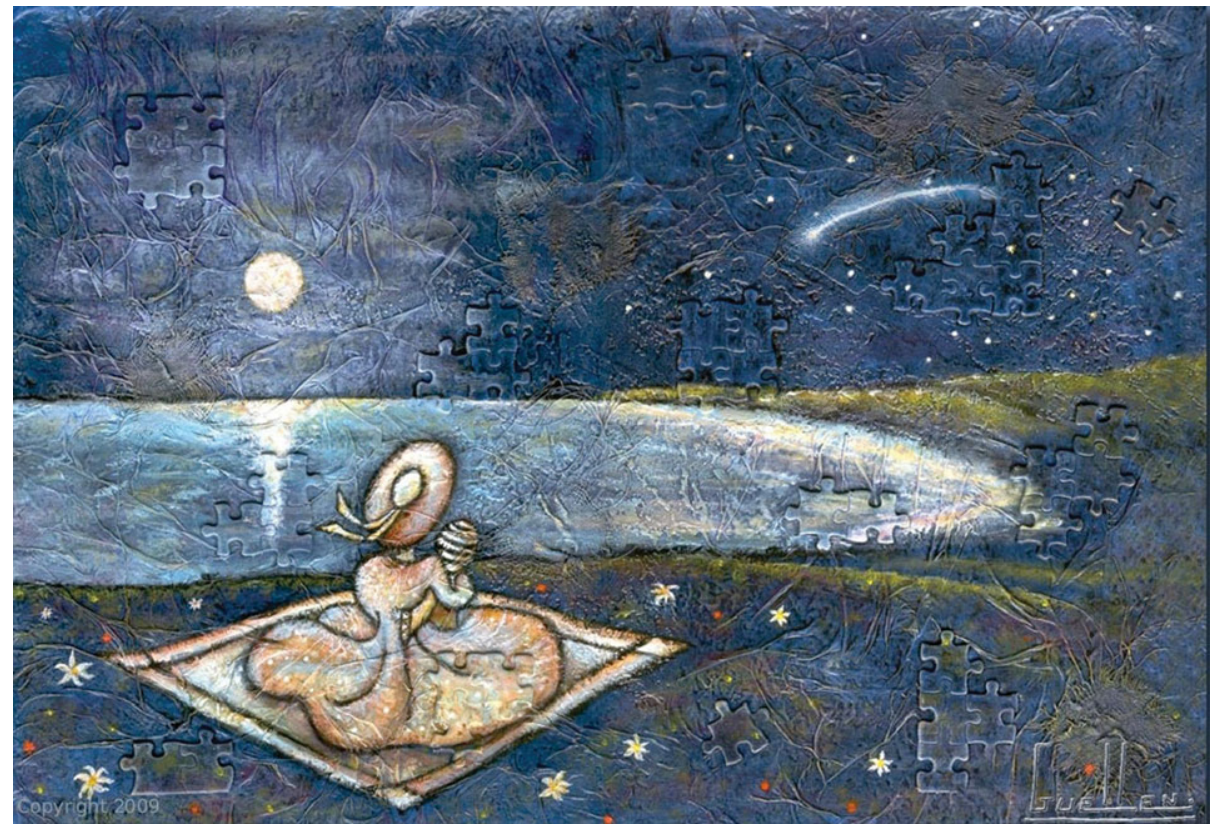

Figure 1. (c) Guellen (2008)

My painting is an invitation to dream which transports you to a universe beyond time. These are magical or delightful moments which speak in poetry, softly and delicately. They lead to a strange yearning for other places, beyond even the firmament. The poetry of the heavens is often represented in my pictures, it is a theme which feeds my imagination without limit.

Hardly suprising, then, that I have now turned to Astronomy and knocked at the door of the Observatoire de Paris.

\section{A collaboration with an astronomer of the Observatoire de Paris}

I have now worked alongside the scientific world for more than two years. A fascinating experience and I like to compare my work as a painter with that of a researcher. These are two similar professions because, even though everything seems to separate the universes of Art and Science, I will show you that this is not quite true!

There are two questions I am often asked. The first: Why does one choose to become a painter?

The second: What are the qualities required to do my job?

You could ask the same two questions to a research worker, he would probably give the same answers!

Stendhal said: "A vocation is to have your passion as your job". Oh, yes! Passion! It is the magic word!

Passion carries us along, it generates enthusiasm. We draw an enormous amount of energy from it.

For the second question, what qualities are required?, I would give the same anwer as a research worker, that one must be inquisitive, creative, bold, rigorous, determined and enthusiastic. 


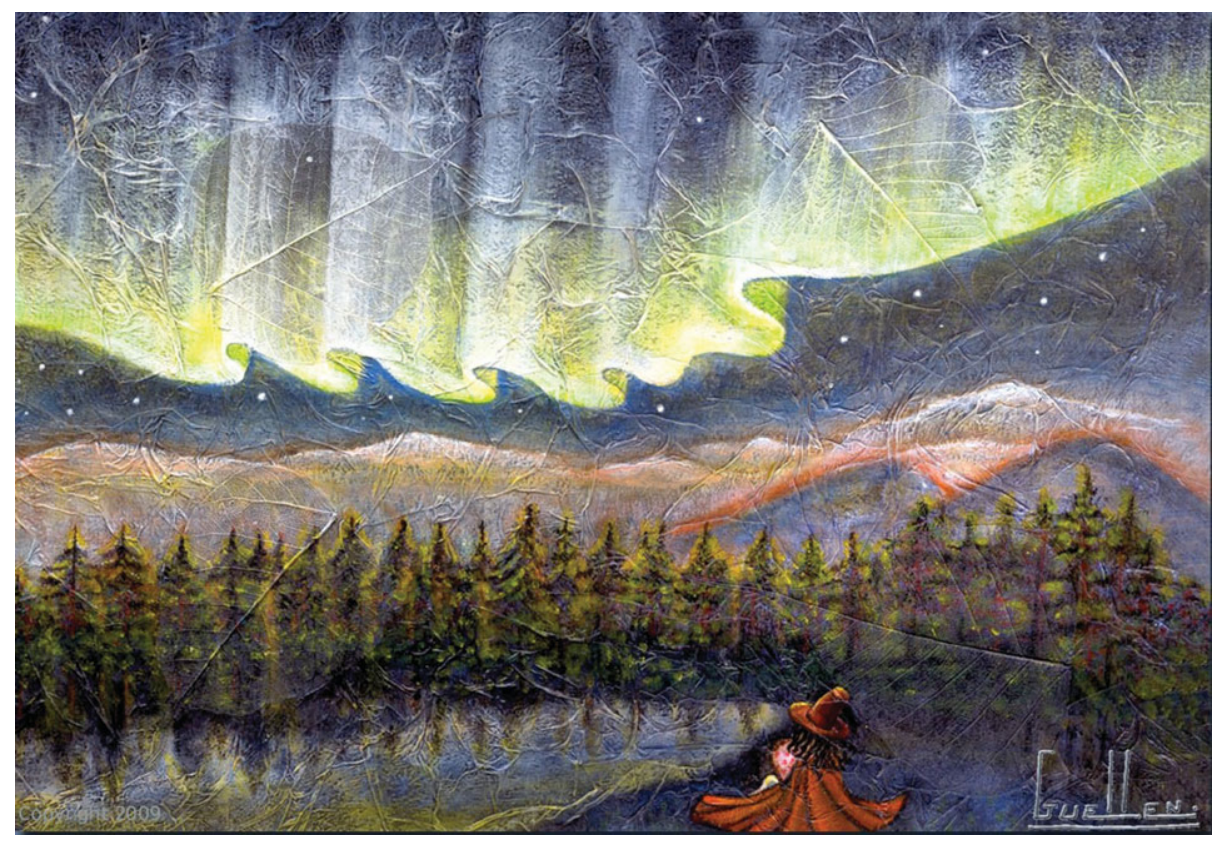

Figure 2. (c) Guellen (2008)

Yes, to become a scientist or an artist you have to be inquisitive. That is, curious about the world around us. Curiosity brings a great thirst for knowledge, an envy to explore, to discover still unknown avenues.

Your spirit has to be inquisitive and creative! Generally it shows in childhood. This spark is quickly recognised. There is a need to express and apply the ideas which well up. One way or another they have to come out!

I am going to refer to passion again. Because if passion carries us on to success, it also enables us to bounce back during those moments of doubt or failure. Failure is a fearsome test to which we can all be exposed. In these moments of doubt, determination, enthusiasm and rigour, are essential qualities for not giving up.

I am a perfectionist. "Vingt fois sur le métier remettez votre ouvrage" Work on the picture 20 times and it still needs retouching, this French proverb for those who are never satisfied illustrates well the path which leads to excellence in our respective disciplines. The research worker, like the artist, cannot make progress in his profession without paying attention to detail and perfection.

pending many months, withdrawn from the world and working all hours, is the life of the artist and scientist alike. Until the moment arrives to expose the work, long in its fulfilment, to the public, to one's peers and certainly to criticism.

We have long understood that the desire of a research worker or a creator is to discover and explore new avenues.

An element of boldness is needed when presenting original and innovative ideas which upset existing practices.

And courage is also required to expose one's work sometimes to flattery and sometimes to harsh judgement. Thus, personality and strength of character are needed so as not to be deflected when doubt or criticism get in the way. In short, resist external influences and hold on to convictions and objectives. 


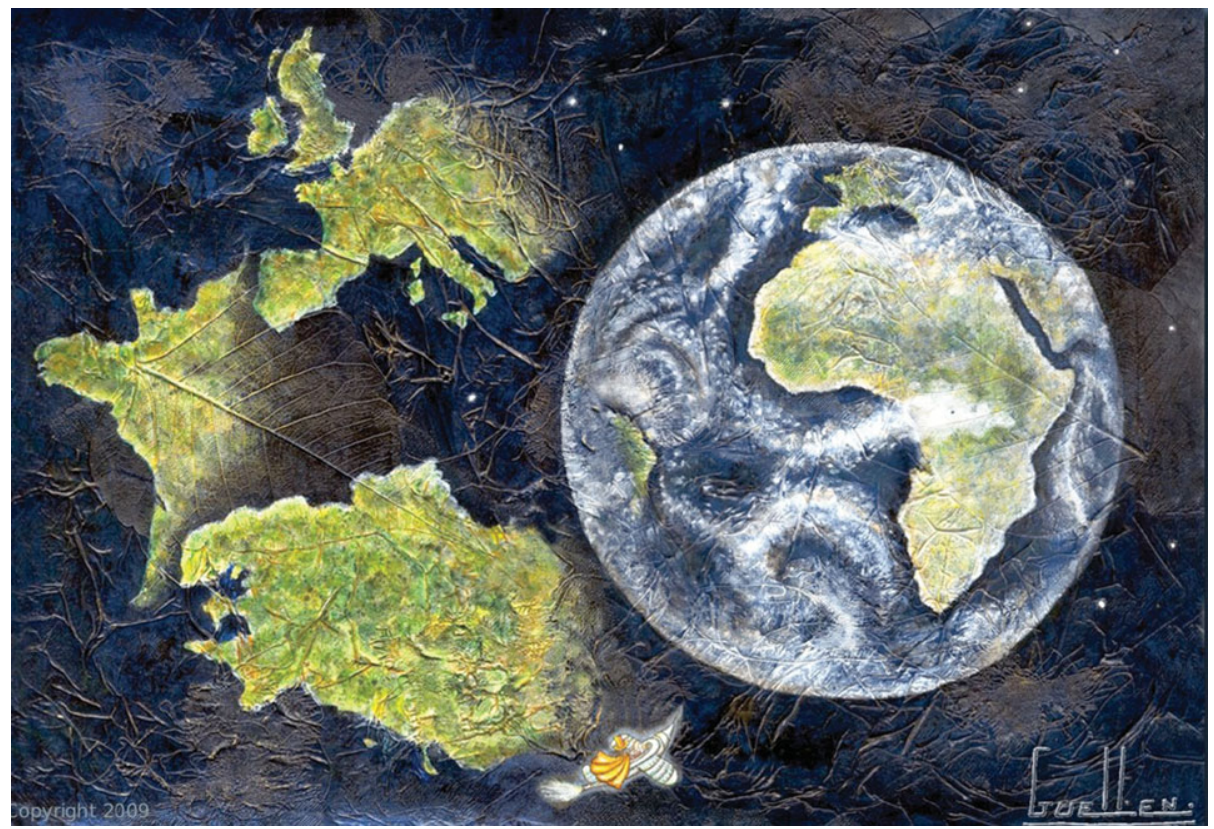

Figure 3. (c) Guellen (2008)

The time factor is an ally for the artist and the scientist. It is always a little suprising when the media announces the retirement at 25 of a top model or when a football player career finishes at 30. With time working against them, this type of activity, of limited span, allows neither full development nor true maturity. In contrast to researchers and creators where experience and know-how are acquired through invaluable practice and apprenticeship. With age the spirit does not stop evolving, stays always sparkling, it bubbles with ideas and projects.

I have just outlined the numerous similar points which effect the Art and Science professions. There is, however, one essential point which separates us: the researcher generally works in a team while the artist is alone in her studio.

During many years I worked alone, up to the moment when I finally found this difficult! I yearned for collaborative projects, the rich experience of sharing and exchanging ideas. For a long time a craving for illustrating childrens' books had been excercising my mind.

\section{Art at the service of science}

If the field of publishing and, more particularly, that of childrens' books effects me especially, it is because I am a mother. Mother of a little girl who is just five years old. I watch her, curious about everything, I see her marvelling at what is around her. She bombards me with questions! Mummy, why this?, why that? .....

Like anyone, I do not always have the answers! My reaction is, therefore, to guide her towards books which know how to capture her curiosity and provide the answers to her questions. She asks for no more than the opportunity to learn. Her brain is a sponge which absorbs one thousand and one bits of information every day.

When my daughter comes into my studio she is fascinated by my pictures. She loves to run her fingers over the painting, feeling the roughness of its surface. And the questions come pouring out again! I sensed that I had here a wonderful means of capturing childrens' 
interest. And to spread knowledge, pass on understanding by means of my painting has become, for me, a reality.

With this in mind, in 2006 I made an important contact, with a researcher in astronomy at the Observatoire de Paris. I suggested the idea to him of a different style of book in the form of a story for little children. A new way of approaching science by merging poetic illustrations with the rigor of scientific knowledge.

This has led to a series of works for children entitled "L'Astronomie des tout-petits", in English this would be "Astronomy for Little Ones". Some ideas on ecology, which is an important subject for us, have also been tackled in this series.

All of us ask ourselves this existential question one day. What is our rôle on Earth? Why are we here? A real need to make sense of one's life. Being an artist, I have asked myself these questions a hundred times. Some painters provoke to upset people and spread scandal about themselves. Others pass on a message, their experiences or their convictions. Through my painting I express my need to pass on emotions. And, because art is an extraordinary means of communication, as an artist and a mother, I identify myself with educational books. And, more particularly, with scientific books. Because, in years to come, in this changing world, science is going to have to rise to major challenges. Above all, for the environment and clean energy. Already, we need to waken the interest of little ones for scientific disciplines so that later they can become well-informed and responsible citizens. And, for some of them, researchers at the leading edge of progress. It is intelligence and human genius that will create a better world, that of tomorrow.

A book can change a life, it can lead to a vocation and children's dreams can bring forth projects. When growing up it is important to pursue one's dreams, to make a note of them in a corner of one's mind.

Antoine de Saint-Exupéry liked the Berber proverb which says: "If you want to trace a straight furrow, harness your plough to a star". So, regarding the "need to make sense of one's life", I, when very small, quickly found my path, but I still needed time to give it a meaning. And I take advantage of this occasion to thank my astronomer colleague François TARIS, for "harnessing my plough to a star".

\section{References}

Guellen \& Taris, F. 2011, La terre à distance (Forcalquier: Le Sablier Editions) 